\section{O declínio da intervenção estatal na economia}

Seminário de Direito Público e Privado - Presença do Estado na economia UFRGS/92

Peter Walter Ashton

Professor de Direito Comercial e

Direito dos Negócios e Mercado de Capitais

\section{Abstract}

The article, based on research undertaken in 1989 by the United Nations, analyses the progressive reduction of the size of the State, Worldwide, as well as the effort, of many countries, specially of eastern Europe, to privatize bloated and inefficient State services.

O Estado existe, fundamentalmente, para viabilizar a existência de uma sociedade humana organizada. Desde milhares de anos o homem tem procurado calibrar o tamanho e principalmente os poderes do Estado. De um lado existem os que defendem idéias anárquicas, desejando o desaparecimento do Estado, posição evidentemente utópica, e de outro há os que propugnam pela existência de um Estado colossal, onipotente que desde o nascimento do ser humano até a morte tudo ou quase tudo supervisiona e regulamenta. É esta uma visão Orwelliana, igualmente utópica e assustadora quanto à primeira dos anarquistas que evidentemente deve ser repelida. Como em tudo, a verdadeira dimensão do Estado deve ser expressa por uma solução intermediária. Diria qua a formulação desta solução neces sariamente deve ter como parâmetro fundamental, como medida de tudo que diz respeito ao Estado, o indivíduo, o ser humano. O Estado deve existir para proteger e auxiliar o homem singular e garantir a sua liberdade individual. Nesta tarefa, de suport do indivíduo, não pode contudo o Estado ignorar outro parâmetro, igualmente im portante, que é o bem social, o bem estar
coletivo, coletividade dentro da qual existe vinte, principalmente, dos efeitos práticos $\mathrm{da}$
Revolução Soviética de 1917, do Nere Deal de Franklin Delano Roosevelt e das teorias macro-econômicas de John Maynard Keynes. Também os postulados morais dos socialistas fabianos tiveram forte influência Finda a segunda guerra mundial, grande número de países, ex-colônias, do terceiro-mundo, ávidos de desenvolvimento, rápido, deslumbrou-se com o aparente sucesso da União Soviética e seguiram em grau maio ou menor o seu modelo político-econômico (que hoje se revela falido), ajudando assim inclusive a fazer da ex-União Soviética, durante algum tempo, uma potência mundial militar, política e econômica. Nos países ex-colônias, nos quais não havia nenhum setor privado significativo, até mesmo mecanismos governamentais rudimentares, passaram a ser considerados agentes superiores do desenvolvimento. O surgimento em profusão do planejamento centralizado e das economias dirigidas não tardou, ja que nestes paises emergentes, geralmente paupérrimos, inexistiam os mecanismos privados inerentes ao mercado livre. Acre ditava-se, por exemplo, nos países da América Latina que a rigidez das estruturas tradicionais exigia vigorosas iniciativa estatais. O México nos parece típico desta mentalidade de evolução. Seguiu-se um fase na qual passou a outorgar-se ao Estado um grande número de prestações de serviços. A "proteção completa" dada pelo Estado, prestador munificiente de toda sorte de serviços, o famoso Welfare State passou a se por todos almejado. Nesta linha de pensamento afirmava-se, com convicção, que todos os cidadãos de um determinado país deviam poder desfrutar, em igualdade de condições, das benesses do Estado e que para alcançar este objetivo, os serviços pleiteados deveriam ser oferecidos com uniformidade em todo o país, reduzindo-se assim desigualdades regionais na distribuição dos recursos estatais. Todas as decisões deveriam ser elaboradas a nível central. Devi imperar uma idéia coletiva do bem estar da sociedade, e jamais uma prestação de serviços baseada em decisões privadas, segundo opiniões individuais daquilo que deveria significar e ser este bem-estar. Embora estas políticas de provisão e previsão social estatal total tenham melhorado a qualidade de vida de muitos, o custo financeiro astronô mico de tais programas somente pode ser suportado, razoavelmente, naqueles países que contam com uma população estável sem significativo crescimento demográfico, povo alfabetizado e capaz de aplicar e utilizar alta e média tecnologia, em todos os campos e áreas de atividade e produção humanas, forte e consciente arrecadação e pagamento de impostos, bem como administração estatal qualificada, dedicada, bem paga e incorruptível, dotada de forte senso, de patriotismo e colaboração com o bem comum. Inexistindo estas condições, que geram a capacidade de produção de riquezas e viabilizam a arrecadação de impostos pelo Estado, é impossível manter, a longo prazo, um Welfare State, pois o déficit público, a inflação debilitante e um inchado serviço público logo se instalam e acabam com toda e qualquer euforia e ilusão.

Estudo relatório elaborado pelas Nações Unidas revela que já a partir da década de 1970 iniciaram-se as críticas aos princípios que informam a política econômica e soacial do Welfare State. O consenso sobre o revelante papel do Estado que parecia tão firme de 1950 a 1970 em muitos países, sem levar em conta a sua organização política, revela-se enfraquecido e tênue ao fim da década de 80 . A importâncoa excessiva atribuída ao Estado, quase invariavelmente redundou em desastre econômico-financeiro e quase falência.

Se trinta anos atrás a prioridade dos planos econômicos era o pleno emprego, alavanca para aumentar a produção e assim incrementar a arrecadação de impostos, hoje em dia a preocupação maior é o combate e o controle da inflação e a melhora da competividade internacional dos países, competividade que presentemente se considera como a condição básica para o crescimento econômico a longo prazo e geradora do pleno emprego.

Informa o estudo das Nações Unidas, por nós consultado, que os altos gastos so- 
ciais, sempre crescentes, são presentemente associados a resultados econômicos estancados. Em que pesem as tentativas feitas, não foi possível estabelecer nenhuma conexão empírica clara e positiva entre o nível dos gastos sociais e a taxa de crescimento econômico, o que parece comprovar que altos gastos sociais não geram, automaticamente como resultado, uma melhoria no desempenho econômico de um país. De outra feita tem-se argumentado que impostos mais altos sobre os salários aumentam o custo do trabalho; que impostos mais elevados sobre os rendimentos desestimulam os investimentos, a poupança e a iniciativa empresarial em geral, e que os déficits propositais vinculados e determinados objetivos geram inflacão.

Argumenta-se ainda que os maciços gastos com o bem-estarsocial geram desestímulos ao trabalho e que todos estes fatores em seu conjunto fomentam uma falta de flexibilidade e atrasam o crescimento. Quer nos parecer que o que temos lido a respeito do estado atual, deplorável, da economia da ex-União Soviética é uma prova cabal do acerto destes argumentos contidos no citado relatório da Organização da Nações Unidas.

Durante as décadas de 50 e 60 , enquanto se expandiam os serviços sociais, acreditava-se que a responsabilidade principal de financiar esta expansão deveria recair sobre os que economicamente estavam melhor Esta convicção mudou a partir do final dos anos setenta, pois constatou-se, na maioria dos países desenvolvidos, que não somente os economicamente mais fracos têm acesso e usufruem dos serviços de seguridade social, mas sim a população em geral sobre a qual recai a carga dos gastos sociais. Ficou patente que o sistema não funcionava como uma redistribuição dos rendimentos dos ricos aos pobres, mas que a incidência principal dos encargos do Welfare State - do Estado provedor - recaía sobre os rendimentos da classe média. Esta, dando-se conta desta situação, passou a oferecer resistência à aceitação de maiores imposições para manter o Estado provedor, resistência ess que ultimamente tem aumentada bruscamente, como demonstram diversas "rebeliões antitributárias" ou "antitaxa" de previdência social, o crescimento de economias subterrâneas, as mais diversas e sofisticadas formas de sonegação de impostos e medidas defensivas similares.

Constata o já citado relatório da ONU que tanto no modelo da previsão social estatal como no que adota uma economia planificada e centralizada, os serviços proporcionados ou financiados pelo setor público crescem desmedidamente, tornando-se por demais vastos e complexos. Com a proliferação de organismos estatais gigantescos, dotados de jurisdições que se superpõem e digladiam, a criação de categorias profissionais burocráticas as mais diversa e uma crescente centralização administrativa, o sistema passa a ser de difícil manejo, não consegue satisfazer adequadamente novas necessidades e muito menos as antigas. Pouco a pouco o sistema passa a mostrar-se menos responsável ante os legisladores principalmente os seus usuários, e a desmedida complexidade permite crescentes abusos e surpreendentemente impossibilita o acesso à assistência social, a muitos com reais necessidades. Outros, desalentados por procedimentos complicados e burocratas pouco sensíveis, ou até ignorantes dos seus direitos, não chegam a utilizar os serviços sociais disponíveis. Se, então, de um lado existe, cada vez mais presente, o problema da fraude no sistema de prestação de serviços de bem-estar, de outra banda se tem constatado, a nível estatístico, que o apoio público/estatal aos miseráveis e/ou muito pobres, aos jovens sem qualquer qualificação profissional, a pais e mães solteiras e a toda sorte de miseráveis discriminados que não possuem conhecimentos remuneráveis, nem pela sociedade nem pelo mercado de trabalho, cria uma dependência viciada e autoperpetuante da ajuda governamental. Impõe-se então uma mudança de objetivo na política de prestação de serviços sociais. É preciso viablizar e ajudar os usuário destes serviços a superar a "dependência de bem-estar", proporcionando capacitação profissional que permita a estes usuários obter trabalho mais facilmente. As experiências realizadas indicam que este sistema/solução alternativo não deve ser coercitivo, mas sim voluntário. Tomada a decisão, a nível governamental/administrativo de adotar esta sistemática, é preciso que a economia do país em que o sistema é implantado, oferta a empregos não-qualificados ou de baixa qualificação suficientes em locais acessíveis, viabilizando também horários flexíveis para atrair mães trabalhadoras ou que cuidem de pessoas incapacitadas ou idosas. É óbvio que estā não é uma solução milagrosa, pois sempre haverá um número significativo de pessoas que por incapacidade mental ou física não tem as condições necessárias para exercer até mesmo estes tipos de empregos e que continuarão dependentes dos serviços públicos.

Afirma-se, com cada vez maior clamor a necessidade de mudança nos serviços sociais e estatais criticados como sendo caros e embrutecedores e que poderiam ser complementados e até mesmo substituídos por sistemas de apoio familiares ou comunitá rios, como por exemplo quando se trata de anciãos e incapacitados.

O valor e a importância da liberdade de opção

Existe a opinião, bastante difundida, de que a regulamentação excessiva da vida social e econômica de qualquer país reduz, sensível senão totalmente a liberdade de opça dos cidadãos, tornando ineficiente a intervenção estatal. A destinação de recursos por força da planificação cultural governamental seguidamente resulta em decisões errôneas e a produção de bens e serviços que não correspondem às necessidades dos consumidores destes bens e serviços. Existem verdadeiras histórias de horror, trágicas e hilariantes ao mesmo tempo, quanto a este tipo de problemática nos países comunistas, principalmente na ex-União Soviética. As inúmeras normas que regem a vida econômica e social dos países comunistas e das economias demasiadamente estatizadas servem para proteger as empresas da concorrência e para proporcionar aos burocratas meios para assegurar-se vantagens pess sem que a Sociedade obtenha qualquer benefício. Talvez a mudança mais importante que está ocorrendo, em larga escala, em muitos países, é o reconhecimento de que é valiosa a liberdade em relaşão d̀ intervencão estatal devido ao que Milton Friedman de nominou, em sua obra Freedom of Choice, a fecundidade da liberdade, porque se reconheceu que a liberdade por si só é produtiva.

O valor decisivo da liberdade em relação à intervenção governamental para aumentar a produção e ampliar o número de opções possíveis possui duas fontes. Em primeiro lugar, permite que a sociedade aproveite o poder criador e o espírito de iniciativa do empresário; em segundo lugar, a liberdade de ação rompe a rigidez das regulamentações e dos sistemas de outorga de licenças que petrificam o status quo e opõem resistência tenaz à mudança e à inovação. O mercados menos regulamentados permitem maior competência e fomentam uma maior eficiência no uso dos recursos.

No que concerne aos serviços de saúde pública, educação e infra-estrutura física, é notório que as economias de mercado, via de regra, apresentam dificuldades intrínsecas para ocupar-se com estes problemas. É, pois, nesta área que deve agir o Estado com

a finalidade de aumentar a gama de possibilidades de opção dos indivíduos de participar da economia de mercado dentro da qual se encontram. Deficiências nestes serviços e outros similares que podem e à vezes devem ser oferecidos pelo Estado, reduzem a capacidade dos cidadãos de participar efetivamente da sociedade em que se encontram e diminuem a mobilidade socia de amplos setores da população de um país.

Existem, naturalmente, soluções intermediárias que procuram, através de concessões outorgadas pelo Estado a empresas particulares para a exploração de serviços que seriam do Estado, proporcionar os serviço solução adotável consistiria em introduzir 
elementos de concorrência entre as instituiç̧ōes privadas que proporcionariam os serviço em lugar do Estado, permitindo aos consumidores que façam a sua escolha. Entre os exemplos citados pela ONU, estão os seguintes: para viabilizar e incentivar a privatização do ensino público os pais receberiam bônus do governo para pagar o custo de qualquer escola que escolhessem para seus filhos em vez de manter escolas públicas ou mandar os estudantes para uma de terminada escola pública. As escolas que possuem as melhores condições na opinião dos pais e estudantes sobrepujariam as demais. De maneira análoga, os médicos mais capazes e os hospitais mais eficientes atrairiam os pacientes segundo a qualidade dos seus serviços.

Outra solução, já amplamente adotada em muitos países, seria o Estado adquirir contratar serviços e bens mediante a licitação pública, de maneira que o governo possa adquirir tais bens e serviços a preços competitivos. Em vários países, governos municipais e estaduais entregaram a prestação e distribuição de determinados serviços com base em licitação pública. Assim ja funcionam serviços de limpeza pública, serviços de limpeza em hospitais públicos outras instalações governamentais, serviço de bombeiros e até mesmo serviços penitenciários.

\section{A propriedade estatal de empresas}

Reporta o Relatório anual (1989) das Nações Unidas que dentro do processo de redefinição do papel do Estado está nitidamente demarcado o abandono das empresas estatais. No passado, os governos nacionalizavam empresas ou constituíam novas pelas razões as mais diversas. Era tido como dogma que a propriedade estatal do alto comando de uma economia ajudaria o governo a planejar centralmente a economia nacional. Acreditava-se que o governo/Estado teria um enfoque mais amplo da economia nacional do que a iniciativa privada que haveria uma inversão maior em capital humano e físico. Acreditava-se também que as relações de direito de trabalho, com governo/Estado sendo o patrão, seriam mais harmoniosas do que as com o setor privado da economia. Outrossim, pontificava-se que a propriedade estatal das empresas, com poder de monopólio, permitiria ao Estado/Empresário proteger melhor o consumidor das conseqüências das falhas do mercado Nada disto se concretizou. Na dé cada de 80 , chegou-se à conclusão de que estes objetivos todos seriam melhor alcançados por força da revitalização da propriedade privada. Dada a cada vez maior interdependência da economia mundial, da complexidade das relações econômicas modernas e dos rápidos avanços da tecnologia tornou-se mais difícil, senão impossível, planificar centralmente, a longo prazo, uma economia nacional.

Acresce, que ficou mundialmente comprovado que a sempre crescente burocratização e criação de "cabides de emprego", políticos ou não, no estilo "Nomenclatura" da ex-União Soviética e dos seus ex-satélites do leste Europeu, ou então no estilo latino-americano, do qual o Brasil, lamentavel mente, não pode ser excepcionado, afogam iniciativas e inovações, eliminando por completo qualquer espírito de concorrência ou competitividade. Os dados estatísticos disponíveis à ONU mostram que as perda e prejuízos nas indústrias do setor público são enormes e perfazem parcela cada vez mais significativa dos déficits estatais. Tam bém o capítulo das relacões laborais não é dos mais felizes nas indútrias estatais ou nacionalizadas. O conflito entre proprietá rio privado e empregados foi substituído pelo conflito entre governo e sindicatos; o governo, obrigado a controlar a inflação, revela-se incapaz de resolver os seus conflitos trabalhistas, cedendo, quase sempre, às reivindicações agressivas, aos reclames corporativistas/burocratas exacerbados pela mesma inflação, incontrolável já, instalando-se então condenável e deplorável círculo vicioso, danoso ao contribuinte, ao consumidor, ao cidadão, enfim, à sociedade em geral.
Igualmente mudou o perfil das economias e das indústrias dos países mais desenvolvidos. Se antigamente despontavam e se sobressaíam, por exemplo, as companhia siderúrgicas e outras fábricas pesadas de infraestrutura, hoje em dia a indústria da prestação de serviços, por exemplo, o turismo, ou informática, adquire importância cada vez maior, sobrepujando em importância a hoje decadente e obsoleta indústria pesada das chaminés poluidoras. Esta brutal mudança da estrutura industrial, ocorrida nos últimos 40 anos, foi causada pela avassaladora dominação dos setores de alt tecnologia e dos serviços, por empresas privadas pequenas e médias, dinâmicas, na quais o relacionamento patrão/empregado é mais informal e pessoal, com marcante interesse de todos os participantes do empreendimento no êxito da empresa. No Reino Unido, o ex-governo Thatcher, com ímpeto e decisão, resolveu, há mais de 8 anos, implementar a privatização das empresa estatais, através da venda no mercado acio nário de capitais. Trata-se do conhecido BesBusiness Expansion Scheme, acoplado ao PEP, ou seja, Personal equity plan, isto é, o plano de participação individual no capital socia de empresas estatais. Ambos os planos contaram com incentivos fiscais específicos.

Também em outras economias de mercado, tais como: a República Federal da Ale manha, a França e o Canadá, onde é forte a presença do capital privado na economia os esforços de privatização existem e continuam, mas são mais modestos, talvez, exa- tamente, porque não existe esta premência, esta urgência de desestatizar e privatiza para reforçar a livre iniciativa e a livre concorrência que nestes países é dominante. País característico desta situação são os Estados Unidos, onde apenas uma pequena parte do mercado corresponde ao setor público.

No Brasil, meritoriamente, foi criado, em 1981, um programa de desestatizacão. governo brasileiro tentou, timidamente, privatizar 108 empresas estatais. Destas 108, 10 empresas foram incorporadas a outras, 4 liquidadas, duas abriram o capital ao público $\mathrm{e}$ as Ceasas foram entregues às administrações estaduais. Segundo informaçōes da Secretaria Especial de Desestatizacão (Zero Hora de 26.02.90, pg. 12), existem 40 empresas consideradas intocáveis.

De tudo quanto foi visto, sobressai a falência, quase generalizada, da empresa estata Falência quanto à produtividade, inovação, dinamização, burocrático-administrativa jurídico/laboral, e sobretudo de modernização. Basta ver o desastre do leste europeu que se patenteia agora ao mundo e que demonstra, irretorquivelmente, que a inexistência ou enfraquecimento da propriedade privada, o excesso de estatização, inexoravelmente, leva a uma qualidade inferior, ou inexistência dos produtos, ao atraso tecnológico, à pobreza generalizada, à ignorância e à infelicidade global da Sociedade em geral, excetuando apenas os que pertencem à elite da nomenclatura burocrática corporativista-partidária-monopolística. 